\title{
The Mixed Blessings of Migration : Life Satisfaction and Self-Esteem over the Course of Migration
}

\section{Lönnqvist, Jan-Erik}

2015

Lönnqvist , J-E , Leikas , S , Mähönen , T A \& Jasinskaja-Lahti , I 2015 , ' The Mixed

Blessings of Migration : Life Satisfaction and Self-Esteem over the Course of Migration ' ,

European Journal of Social Psychology, vol. 45 , no. 4 , pp. 496-514 . https://doi.org/10.1002/ejsp.2105

http://hdl.handle.net/10138/234338

https://doi.org/10.1002/ejsp.2105

acceptedVersion

Downloaded from Helda, University of Helsinki institutional repository.

This is an electronic reprint of the original article.

This reprint may differ from the original in pagination and typographic detail.

Please cite the original version. 


\section{Accepted author manuscript.}

Lönnqvist, J. E., Leikas, S., Mähönen, T. A., \& Jasinskaja-Lahti, I. (2015). The mixed blessings of migration: Life satisfaction and self-esteem over the course of migration. European Journal of Social Psychology, 45(4), 496-514.

The Mixed Blessings of Migration 1

Running Head: The Mixed Blessings of Migration

The Mixed Blessings of Migration - Psychological and Social Well-Being over the Course of Migration

Jan-Erik Lönnqvist

Swedish School of Social Science, University of Helsinki, Finland

Sointu Leikas

Institute of Behavioural Science, University of Helsinki, Finland

Tuuli Anna Mähönen

Department of Social Research, University of Helsinki, Finland

Inga Jasinskaja-Lahti

Department of Social Research, University of Helsinki, Finland

Author Note

This research was supported by the Academy of Finland research grants 123297, 257079, and 1266076. We would like to thank Tamara Kinunen (St'Petersburg State University, Russia), Michail Vinokurov (State University of Petrozavodsk, Russia), as well as Elina Leinonen, Jesse Haapoja and Elena Waschinski (Department of Social Psychology, University of Helsinki, Finland) for their help in data collection and coding.

Correspondence concerning this paper should be sent to Jan-Erik Lönnqvist, Swedish School of Social Science, University of Helsinki, PO BOX 16, 00014 University of Helsinki, Finland. Phone: +35891911. Email: jan-erik.lonnqvst@helsinki.fi 


\begin{abstract}
We investigated the psychological adaptation of Ingrian-Finnish migrants from Russia to Finland between 2008 and 2013. Pre-migration data $(N=225)$ was collected at the Finnish language courses that were part of the immigration training program organized by the Finnish authorities in Russia. The three post-migration follow-ups were conducted approximately a half $(N=155)$, two $(N=133)$, and three $(N=85)$ years after migration. We assessed psychological and social well-being at all four time points: Life Satisfaction increased steadily, Self-Esteem decreased steadily, and Social Support showed a U-curve. Certain postmigration experiences - acculturation stress, difficulties adapting, difficult subjective economic situation - were associated with lower social and psychological well-being. The Self-Esteem of participants with high pre-migration General Self-Efficacy showed a weaker decline. The results show that migration may be differently associated with different types of well-being.
\end{abstract}

Keywords: Well-being, Life Satisfaction, Self-Esteem, Social Support, Migration, SelfEfficacy 


\section{The Mixed Blessings of Migration}

Moving to another country involves a series of major life events, and could be expected to have a wide variety of important psychological and social consequences. In this pre-post study of migration, we follow, in a sample of Ingrian-Finnish migrants from Russia to Finland, changes in three variables reflective of well-being: Life-Satisfaction (LS), SelfEsteem (SE), and Social Support (SS). Previous empirical research regarding the effects of migration on well-being has provided conflicting results: some studies on migrants have found high levels of psychological adjustment, but others have reported poor adaptation outcomes (for a review, see Berry \& Sam, 1997). One explanation for the conflicting empirical results could be difficulties in determining with which group to compare migrants. For example, should migrants be compared with other migrants, their counterparts in the country of emigration, or with natives? Further complicating such comparisons is the positive self-selection effect, also called the healthy immigrant effect: migrants generally tend to be better off than those who do not migrate (e.g., Brücker \& Trübswetter, 2007). A third complication is the "immigrant paradox" or "epidemiologic paradox", also called the "health behaviour hypothesis": migrants have more favorable health behaviors and risk factor profiles than non-migrants, which result in their relative health advantage, despite the stressful experiences and poverty often associated with immigration (e.g., Markides \& Coreil, 1986, Rumbaut, 1999). A longitudinal design, in which migrants' post-migration well-being is compared with their pre-migration well-being, averts the difficulties involved in finding an appropriate group with which to compare the migrants. However, studies including both preand post-migration measurement points are extremely scarce. Excluding studies on student populations taking part in short-term mobility programs, only the research by Tartakovsky (2007; 2008; 2009a; 2009b) on a sample of high-school adolescents immigrating alone from Russia or Ukraine to Israel has included both pre- and post-migration measurements. The present research is designed to help fill this gap in the literature.

The purpose of the present research is two-fold. First, we investigate the long-term 
effects of voluntary migration on SS, SE, and LS, assessed at the pre-migration stage (T0), and at approximately half a year (T1), two and half (T2), and three and a half (T3) years after migration. Second, as the effects of migration may not be uniform, we also seek to identify individual-level predictors - demographic variables, economic situation, General SelfEfficacy (GSE), acculturation experiences, perceived discrimination, and acculturative stress - that could be expected to be associated with changes in LS, SE, and SS.

\section{Life-Satisfaction}

The set-point theory of subjective well-being (e.g., Brickman \& Campbell, 1971), also known as the hedonic treadmill model (Diener, Lucas, \& Scollon, 2006), considers subjective well-being a stable, largely genetically determined characteristic (e.g., Headey \& Wearing, 1989; Lykken \& Tellegen, 1996). Although the model, typically supported by studies recording the influence of major life-events on well-being, concedes that major life events may affect well-being, such effects are conceived as temporary - people are thought to adapt to changes in their lives and to revert back to their set-points after a year or two (Brickman \& Campbell, 1971; Clark, Diener, Georgelis, \& Lucas, 2008). This view has recently been challenged by data from several large-scale surveys. These studies, for example, suggest that happiness does change in the long term (e.g., Fujita \& Diener, 2007; Diener et al., 2006). Despite the accumulating evidence suggesting that happiness changes across the life course, the role of major life events in changing personal and social well-being remains unclear. For instance, a review by Clark et al. (2008) that focused on the effects of, for instance, marriage, divorce, widowhood, and the birth of a child, found that only long-term unemployment had a negative effect on happiness, and did not identify any life events with positive effects.

Further, it has been suggested that different components of subjective well-being are more or less reactive to changing life situations (Diener, Ng, Harter, \& Arora, 2010), which may also contribute to the mixed results.

LS refers to the cognitive evaluation of one's life (Diener, 1984), "global” well-being, happiness and satisfaction with life as a whole (Andrews \& Robinson, 1991). This 
component of subjective well-being is more likely to respond to changes in living conditions as compared to the affective component (Diener et al., 2010). Although psychological wellbeing is the most frequently studied migration outcome (Rudmin, 2009), exact predictions are difficult to make.

Adapting to the many changes resulting from migration could be expected to pose a challenge to the well-being of the individual (e.g., Berry, 2006). However, studies on the well-being of immigrants as a function of time spent in the host country have produced very mixed results. At first glance, research seems to typically support a U-curve in well-being: well-being is at its lowest immediately after migration, after which it gradually increases with time in host country (Kuo \& Roysircar, 2006; Ward, Okura, Kennedy, \& Kojima, 1998; Ying, 2005). Such results, obtained using only post-migration measurement points, were confirmed in the study by Tartakovsky (2009a), who used also a pre-migration measurement point in his sample of adolescent immigrants to Israel. He found that during the migration process, several measures reflective of well-being (e.g., body image, school competence) followed a U-curve: they decreased in the first year after migration and increased in the third year after migration. Tartakovsky (2009a) argued that the initial disappointment and disillusionment typical for ethnic migrants are likely to have faded by the third year after migration.

A more careful look at previous studies shows, however, that migration has been related to mental health in a larger variety of ways: positively, negatively and in a curvilinear fashion. In the first thorough meta-analysis of 30 studies on the relationship between acculturation and mental health among Hispanics, Rogler, Cortes and Malgady (1991) found support for all three predictions; 12 studies supported a positive relationship between acculturation and mental health, 13 supported a negative relationship, and two produced both positive and negative effects. Ten years later, Shen and Takeuchi (2001) reviewed 15 empirical studies recently conducted in the United States and found no support for a curvilinear relationship. Six of the reviewed studies showed that acculturation was inversely 
associated with depression among different populations, three studies yielded a positive relationship between acculturation and elevated psychological disturbances, four studies failed to find any significant relationship between acculturation and mental health outcomes, and finally, two studies demonstrated mixed results. These contradictory findings may be explained by the diversity in the particular definitions and measures used to assess adaptational outcomes such as psychological well-being and health status (Nguyen, Messe \& Stollak, 1999; Birman \& Trickett, 2001; Shen \& Takeuchi, 2001).

Considering the use of LS as a proxy of psychological adaptation among migrants, as well as the fact that migration is often motivated by a wish to improve one's life situation in one way or another, successfully pursuing this goal could be expected to result in linearly increased LS. For instance, in the present context, migration may partly be motivated by the higher material prosperity of the host nation. The standard of living is clearly higher in Finland than in Russia - the Human Development Index of the United Nations Development Programme, which includes measures for a long and healthy life, access to education and a decent standard of living, ranked Finland no. 12 and Russia no. 73 in 2008, the year of the pre-migration assessment. Because material prosperity is strongly associated with LS (e.g., Diener, Diener, \& Diener, 1995; Diener, Ng, Harter, \& Arora, 2010; Stevenson \& Wolfers, 2008), moving to a country with a higher standard of living could be expected to increase LS. In light of the above reviewed contradictory findings, we refrained from forming a directed hypothesis regarding changes in LS.

\section{Self-Esteem}

Chamberlain (1988) suggested a distinction between inner- vs. outer-focused evaluations of subjective well-being. LS judgments incorporate both inner- and outer-focused evaluations: i.e., not only the self, but also one's work, family, social, and living environment are evaluated. By contrast, SE, referring to a stable sense of personal worth or worthiness (Rosenber, 1968), is primarily inner-focused. SE is strongly associated with many other measures of well-being. It is, for instance, positively associated with both cognitive (Diener 
\& Diener, 1995) and affective evaluations of life (Brown \& Marshall, 2001; Heatherton \& Polivy, 1991), and negatively associated with depression (Tennen \& Herzberger, 1987) and loneliness (Jones, Freemon, \& Goswick, 1981).

Some research has suggested that SE is not distinguishable from trait Neuroticism (Judge, Erez, Thoresen, \& Bono, 2002). Considering that adult personality traits do not tend change as a function of life-events (e.g., Specht, Egloff, \& Schmukle, 2011), one could expect SE to remain stable throughout the migration process. However, in his sample of adolescents immigrating to Israel, Tartakovsky (2009a) found a U-curve in SE; after an initial post-migration decrease, SE gradually started increasing. However, this U-curve could be specific to adolescents, whose personality is still developing and who might therefore be more responsive to life-events. As in the case of LS, we decided to refrain from making directed predictions regarding SE.

\section{Social Support}

The understanding of well-being is shifting from the individual's subjective perception of his or her life to include also a social dimension (e.g., Keyes, 1995; Huppert et al. 2009); this dimension constitutes an outer-focused evaluation of life. There are different constructs that could be used to study social well-being. Social networks (Helliwell \& Putnam, 2005), social capital (Helliwell, \& Barrington-Leigh, 2010; Putnam 2000) and group belonging (Jetten, Haslam \& Haslam, 2011) are all important markers of life quality and determinants of human health. However, in the context of immigration research, SS is probably the most frequently studied construct indicative of social well-being. Yet there is no single generally accepted definition of SS. On a very general level, it refers to helpful functions, including both instrumental and emotional support, performed for an individual by significant others such as family members, friends, colleagues, and relatives (Thoits, 1985). Such support conveys to a person that he or she is cared for and valued and is typically associated with health, well-being, and reduced psychological distress (Beehr \& McGrath, 1992; Cohen \& Wills, 1985; Heller, 1979; House, 1981; Thoits, 1985; Turner, 1982). SS has 
also been frequently linked with both cognitive (Pinquart \& Sörensen, 2000; Young, 2006) and affective (Diener, Sandvik, \& Pavot, 1991) measures of well-being, and has been found to mediate the effects of other variables, such as social network size and personality traits, on well-being (Zhu, Woo Porter, \& Brzezinski, 2013).

In the process of migration, many social relationships are likely to be severed, and new ones will take time to build. SS could therefore be expected to show a U-curve over time; plummeting at the first post-migration follow-up, but gradually increasing at the second and third follow-ups. Consistent with this idea, loneliness followed an inverted U-curve in the study by Tartakovsky (2009a).

\section{Individual Difference in Change}

Besides examining the effects of migration on long term LS, SE, and SS, we aim to identify possible individual differences associated with these three variables. Background characteristics, such as age and whether one is moving alone could be expected to affect changes in well-being. We expected the elderly to experience more difficulties in the migration process due to the loss of social roles and statuses, increased physical disability, and percevied service discrimination based not only on racism but also on ageism (Blakemore \& Boneham, 1994; Manthorpe \& Hettiaratchy, 1993).

Post-migrations experiences are likely to have a strong impact on migrants' wellbeing. A previous study (Mähönen \& Jasinskaja-Lahti, 2013) using the same sample of Ingrian Finns - but only one post-migration assessment and a different measure of well-being - showed that difficulties in socio-cultural adaptation (Brisset, Safdar, Lewis, \& Sabatier, 2010), acculturative stress (Lazarus \& Folkman, 1984), and experiences of discrimination (Berry et al., 2006; Jasinskaja-Lahti et al., 2006) are all relevant in predicting migrants' wellbeing. However, subjective economic situation, one of the most important determinant of immigrants' well-being (Rudmin, 2009; Kessler, Mickelson, Williams, 1999), and likely to influence both LS (Ackerman, \& Paolucci, 1983) and SE (Twenge \& Campbell, 2002), was not included in the previous study (Mähönen \& Jasinskaja-Lahti, 2013). We now wanted to 
confirm that post-migration experiences matter even when the economic situation of the migrants is controlled for. Based on previous research, we expected difficulties in sociocultural adaptation, acculturative stress, perceived discrimination, and a difficult economic situation to predict lowered well-being among immigrants.

Individuals may differ not only in their migration experiences, but also in their skills and psychological resources to adapt to the life changes and the acculturative stress that migration causes. The research seeking to identify individual difference variables that could explain adaptation outcomes has produced somewhat mixed results (Berry \& Sam, 1997), although a general trend seems to be that characteristics generally considered beneficial for well-being, such as emotional stability, extraversion, and secure attachment, are also beneficial in a migration context (Bakker, Van Oudenhoven, \& Van der Zee, 2004; Schmitz, 2004; Ward, Leong, \& Low, 2004). Given that the migration process is often experienced as distressing (Berry, 2006), individual characteristics that aid coping with stressors could be expected to be especially important in facilitating adaptation. GSE - representing a broad and stable confidence in one's ability to deal with different demanding situations - is associated with better coping strategies (Stewart, \& Yuen, 2011). GSE has been shown to facilitate adjustment to potential stressors, such as abortion (Cozzarelli, 1999) or starting work (Saks \& Ashforth, 2000). In a migration context, Tartakovsky (2009a) reported that psychological resources buffer acculturative stress and homesickness in immigrants. Based on the above results we expected GSE, assessed at the pre-migration stage, to be associated with higher post-migration well-being.

\section{Purpose of the Present Research}

To sum up, the aim of the present research was to investigate, in a sample of migrants, the long-term changes in both inner- and outer-focused evaluations of life quality. Our first goal was to examine the effects of migration on long term LS, SE, and SS. Regarding the two former, we refrain from making directed predictions. However, we expected SS to show a Ucurve. Our second goal was to identify possible individual differences associated with 
changes in LS, SE, and SS. More specifically, we expected high age, difficulties in sociocultural adaptation, acculturative stress, perceived discrimination, and poor subjective economic situation to have detrimental consequences for well-being. On the other hand, we expected heightened GSE to be associated with higher post-migration well-being.

Our participants constitute a subsample of a larger longitudinal research project investigating the migration of Ingrian-Finns and their family members to Finland between 2008 and 2013. The current paper can be considered a sequel to the paper by Mähönen and Jasinskaja-Lahti (2013), who showed that individual differences in post-migration adaptation experiences, acculturative stress, and perceived discrimination, were all associated with postmigration psychological well-being. This previous paper used only pre-migration data and post-migration data from the first follow-up. By contrast, the present papers reports on premigration data and on data from three follow-ups. This not only extends the time range of the study by three years, which is by itself important as many changes and even reversals are likely to take place during the first three years (Lönnqvist, Jasinskaja-Lahti, \& Verkasalo, 2013; Tartakovksy 2009a, 2009b), but also allows the use of more sophisticated statistical analyses; i.e., latent growth modelling. This is particularly important as some of the changes that we investigated were expected to be curvilinear. Another difference between the studies is the dependent variable; Mähönen and Jasinskaja-Lahti (2013) employed the General WellBeing Index (Gaston \& Vogl, 2005), which was only administered at the two first measurement points. We measured changes in psychological and social well-being using measures that were administered across all four measurement occasions; i.e., measures of LS, SE, and SS.

\section{Method}

\section{Participants and Procedure}

The present study focuses on Ingrian Finns, the offspring of Finnish colonizers who settled down in Ingria area (now in Leningrad Oblast) in the 17th century. After the Russian conquest in 1703 many remigrated back to Finland. Of those who remained, many 
disappeared in the forced population transfers before and after WWII. Between 1990 and 2011, the remaining Ingrian Finns in Russia were granted the right to remigrate by Finnish Law of Return.

The pre-migration data of this study comes from the baseline of the longitudinal INPRES (i.e., Intervening at the pre-migration stage: Providing tools for promoting integration and adaptation throughout the migration process) project. The baseline consisted altogether of 225 potential Ingrian Finn migrants living in the Republic of Karelia or the Leningrad area. The pre-migration data was collected at the Finnish language courses that were part of the immigration training program organized by the Finnish authorities in Russia during April and May 2008 (T0). The INPRES project included two follow-ups, conducted first between October 2009 and April 2010 (T1, $N=155 ; 111$ female; age $M=45.5$ years, $S D$ =14; migration had occurred around half a year ago), and then between December 2011 and April 2012 (T2, $N=133$; 97 female; age $M=46.3$ years, $S D=14$; migration had occurred around two years ago). Thirty participants reported at $\mathrm{T} 1$ having migrated without any other family member. The final follow-up, conducted between September 2012 and January 2013 (T3), was collected as a part of the LADA (i.e., Longitudinal analysis of diaspora migration from Russia to Finland) research project, which complements the data sets collected within the INPRES project with a third follow-up. The participants were reached through contact information from the national population register. Of the 112 potential participants who had at T2 given their permission to contact them for a final T3 follow-up, 85 (62 female; age $M=$ 49.3 years, $S D=14)$ took part $(76 \%$ response rate). At this time participants had lived in Finland for approximately three years $(M=34$ months, $S D=3.9$, range 27 to 40$)$. A series of one-ways ANOVAs revealed that those who took part in the final follow-up did not differ from those who did not on any of the here reported on pre- or post-migration measures.

\section{Measures}

The participants answered the pre- and post-migration questionnaires in Russian: the measures were back-translated from previously reported English versions to Russian by 
official translators and native Russian-speakers.

LS. We measured LS with the Shortened Diener's Satisfaction with Life Scale (SWLS; Pavot, 1993). This scale contains four items that were rated on scale from 1 (strongly disagree) to 5 (strongly agree). An example item is 'In most ways my life is close to the ideal'.

Self-Esteem. SE was measured with four items of the Rosenberg Self-Esteem Scale (RSES; Rosenberg, 1965). At T0, the entire 10-item RSES was administered. We conducted a factor analysis in order to select four items to be administered at all subsequent measurement points. The two items with the strongest positive loadings (items 6 and 7) and the two items with the strongest negative loadings (items 3 and 10) were selected. An example item is 'On the whole, I am satisfied with myself'. The items were rated on scale from 1 (strongly disagree) to 5 (strongly agree).

Social Support. To measure SS, we used the perceived available support scale of the Berlin Social Support Scale (Schulz \& Schwarzer, 2003). An example item is 'When I am worried, there is someone who helps me'. The items were rated on a scale from 1 (strongly disagree) to 5 (strongly agree).

General Self-Efficacy. GSE was measured with the ten items of the General SelfEfficacy Scale (Schwarzer \& Jerusalem, 1995). An example item is 'I am confident that I could deal efficiently with unexpected events'. The items were rated on a scale from 1 (strongly disagree) to 5 (strongly agree).

Adaptation Experiences. The Socio-Cultural Adaptation Scale (SCAS) is a 29-item scale developed by Ward \& Kennedy (1999) that measures an individual's ability to interact effectively in a new cultural environment. Participants rated themselves on a 5-point Likerttype scale ranging from 1 (no difficulty) to 5 (extreme difficulty) in response to the following question stem: Please indicate how much difficulty you experience in Finland in each of these areas. Sample items include the following: dealing with people staring at you, finding food you enjoy, using the transport system, and making yourself understood. 
Acculturative Stress. Stressfulness of the relocation was assessed using four items. We asked participants, 'Compared to other situations in your life, how stressful would you rate (i) moving from Russia, (ii) moving to Finland, (iii) your own adjustment to Finland. The content of the three items was our own, but their structure was based on the work of Aldwin \& Revenson (1987). The response scale, based on the work of Terry (1994), ranged from 1 (Not severe at all) to 7 (The most severe event I have ever faced).

Perceived Discrimination. Participants' perceptions of ethnic discrimination were measured with four items adapted from a scale previously used by Berry, Phinney, Sam, and Vedder (2006). An example item is 'Native Finns have teased or insulted me because I'm an Ingrian Finn'. The response options were 1 (no), 2 (probably no), 3 (can't say), 4 (probably yes) and 5 (yes).

Subjective Economic Situation. Participants' perceptions of their economy were measured with one item asking 'How is the current economic situation of your household?' (Liebkind et al., 2004). The response options ranged from 1 (We can more than cover our expenses and still have some left over) to 5 (We are forced to cut back on all of our consumption and still cannot make ends meet). Subjective indicators of economic situation are highly correlated with objective indicators; we decided to use the former because they are more strongly associated with assessments of subjective well-being (Ackerman, \& Paolucci, 1983).

\section{Results}

Table 1 shows the means, standard deviations, and alpha internal consistency reliabilities of our measures. The means do not indicate the presence of potential ceiling or floor effects, and the standard deviations look reasonable. With one exception, all internal consistency reliabilities were adequate, exceeding .70. The exception was T3 SE, which had an internal consistency reliability of .56. Even this number is not alarmingly low, considering that the measure was only four items long.

\section{Unconditional Latent Curve Models.}


All analyses were conducted with the MPlus 7 statistical package (Muthén \& Muthén, 2007). Latent growth curve modelling and Full Information Maximum Likelihood Estimation (FIML) were utilized. The FIML method (e.g. Enders \& Bandalos, 2001) uses all available information from all time points (i.e., the responses of all participants were utilized, regardless of the number of measurement points at which they provided data).

In order to examine the overall change in LS, SE, and SS, unconditional latent curve models (LCMs) in which intercept and slope were modelled as latent variables, and observed means as their indicators, were applied. In case of a poor fit of a linear model, a quadratic latent term was added. If the model showed poor fit even after the addition of a quadratic term, a free growth model was used in which two of the four time scores were estimated freely (i.e., a model testing the possibility of more complex change pattern). The results of the unconditional LCMs are shown in Table 2.

Life Satisfaction. The linear model for LS had poor fit $\left(\chi^{2}(7)=43.10, p<.001, \mathrm{CFI}=\right.$ $.591, \mathrm{RMSEA}=.156)$. The quadratic model had better, but still inadequate fit $\left(\chi^{2}(6)=23.21\right.$, $p<.001, \mathrm{CFI}=.805, \mathrm{RMSEA}=.116)$. However, a free growth model in which scores at T2 and T3 were freed showed good fit $\left(\chi^{2}(5)=9.89, p=.078, \mathrm{CFI}=.948, \mathrm{RMSEA}=.068\right)$, suggesting that the change in LS was non-linear, and this model was retained as the final model. Model results showed that the mean intercept, corresponding to the latent mean at T0, was 2.81 , and that the mean slope, corresponding to the latent mean change over the followup period (T0 to T3), was $0.42(p<.001)$. This increase in $L S$ is depicted in Figure 1 (top panel). Slope and intercept were uncorrelated $(r=.10, p=.709)$, meaning that changes in LS did not depend on its initial level. The slope variance was not significant $\left(\sigma^{2}=.04, p=.829\right)$, suggesting a uniform pattern of change across participants.

Self-Esteem. Regarding SE, the linear $\left(\chi^{2}(6)=63.07, p<.0001, \mathrm{CFI}=.67\right.$, RMSEA $=.209)$ and quadratic models $\left(\chi^{2}(2)=18.64, p<.001, \mathrm{CFI}=.905, \mathrm{RMSEA}=.195\right)$ had poor fit. However, a free growth model showed good fit $\left(\chi^{2}(4)=11.37, p=.023\right.$, CFI $=.958$, RMSEA = .092), suggesting that SE change followed a non-linear pattern. The free growth 
model was retained as the final model. The initial level of SE (latent intercept mean) was 4.29, and the latent mean slope was $-.04(p=.059)$. SE thus decreased marginally statistically significantly during the follow-up (see Figure 1 centre panel). Slope variance was not significant $\left(\sigma^{2}=.012, p=.292\right)$. Slope and intercept were marginally statistically significantly negatively correlated $(r=-.02, p=.099)$, suggesting that those participants who had higher initial SE decreased slightly less in SE.

Social Support. For SS, the linear model had poor fit $\left(\chi^{2}(5)=28.41, p<.0001, \mathrm{CFI}=\right.$ .764$, RMSEA $=.146)$, but the quadratic model had excellent fit $\left(\chi^{2}(1)=1.26, p=.324, \mathrm{CFI}=\right.$ 0.997, RMSEA = .034). Model results showed that the mean latent intercept was 4.55, the mean linear slope was -.24 ( $p<.001)$, and the mean quadratic slope was $.05(p<.001)$. The expected $U$-curve in $S S$ is depicted in Figure 1 (bottom panel). Both the linear and quadratic slopes were uncorrelated with the intercept $(|r| \mathrm{s}<.03$, ps $>.284)$, and slope variances were not significant $\left(\sigma^{2}=.120, p=.372\right.$ for the linear slope and $\sigma^{2}=.009, p=.255$ for the quadratic slope).

\section{Conditional Latent Curve Models}

Our second goal in this research was to identify possible individual differences associated with changes in LS, SE, and SS. In order to examine the role of demographic variables and time-invariant and time-varying psychological covariates in changes in LS, SE, and SS, a series of three types of conditional LCMs were conducted. The conditional models were always built upon the best unconditional LCMs. First, demographic LCMs were built in which the intercept and slope were regressed on time-invariant demographic covariates of sex, age, and whether the participant migrated alone. Second, LCMs including GSE, which was modelled as a time-invariant covariate (TICs), were built. Third, models with timevarying covariates (TVCs) - Adaptation Experiences (T1 and T2), Acculturative Stress (T1 and T2), Perceived Discrimination (T1 and T2), and Subjective Economic Situation (T0, T1, T2, and T3) - were built. For each well-being variable, we first present the TIC models that include GSE. We then present the TVC models that include all of our time-varying 
covariates. In these models, we first investigate whether the covariates are associated with the latent mean or intercept of the well-being variable. For more exploratory purposes, we then report on prospective associations among variables, as well as on concurrent associations. Only statistically significant or marginally statistically significant associations are reported.

Life Satisfaction. The conditional LS models were based on the free growth model. All models had good to excellent fit. In the demographic model, age was significantly related to slope $(\beta=.79, p=.043)$; contrary to expectations, older participants' LS increased more strongly. The TIC model showed that GSE was positively related to initial LS ( $\beta=.49, p<$ $.001)$, but negatively related to the slope of LS ( $\beta=-.31, p=.036)$; those scoring high on LS were initially more satisfied, but their satisfaction increased less sharply in the migration process.

The TVC model showed that initial level of LS was negatively related to T0 Subjective Economic Situation $(\beta=-.43, p<.001)$ and T1 Perceived Discrimination $(\beta=-$ $.38, p=.035)$. Those initially more satisfied with their lives, perceived their initial economic situation to be better and also perceived less post-migration discrimination at T1. Slope was positively related to T0 Subjective Economic Situation $(\beta=.70, p=.002)$ and negatively to T3 Subjective Economic Situation $(\beta=-.71, p=.009)$. Those who were initially economically worse off increased more in LS, but those who experienced economic difficulties at T3 experienced a weaker increase in LS. No prospective relations emerged. T1 LS was negatively related to T1 acculturative stress $(r=-.17, p=.042)$ and T1 Socio-Cultural Adaptation Experiences $(r=-.15, p=.043)$; those less satisfied with their lives at T1 were experiencing more acculturative stress and more difficulties in adapting.

Self-Esteem. The conditional SE models were based on the free growth model. All models had good to excellent fit. The demographic model for SE showed that age was negatively related to the intercept $(\beta=-.22, p=.006)$; younger participants had higher initial SE. No other demographic effects emerged.

The TIC model showed that GSE $(\beta=.50, p<.001)$ was related to initial SE. 
Furthermore, GSE was negatively related to slope $(\beta=-.32, p=.002)$. As the mean slope was negative, this means that those with higher initial GSE decreased less in SE over the followup.

The TVC model showed that T1 Socio-Cultural Adaptation Experiences were negatively related to initial SE $(\beta=-.47, p=.001)$, and that T2 Socio-Cultural Adaptation Experiences were negatively related to slope $(\beta=-.68, p=.013)$. Because low scores on Socio-Cultural Adaptation Experiences indicated experiencing fewer problems, the negative associations suggest that those with initially high levels of SE experienced fewer difficulties at T1, and that SE decreased less for those who had experienced fewer difficulties at T2. T2 Subjective Economic Income was positively related to slope $(\beta=.66, p<.001)$, meaning that those who experienced more economic difficulties experienced a greater drop in SE.

Regarding prospective relations, T1 acculturative stress had a negative association with T2 SE $(\beta=-.15, p=.052)$; those who experienced more acculturative stress at $\mathrm{T} 1$, had lower SE at T2. Furthermore, T2 Subjective Economic Situation was marginally statistically significantly associated with T3 SE $(\beta=-.75, p=.070)$, suggesting that those who experienced more economic difficulties at T2 had lower SE at T3. T2 SE was correlated with T2 acculturative stress $(\mathrm{r}=-.20, p=.007)$, but no other concurrent relations emerged.

Social Support. The conditional SS models were based on the quadratic model. All models had good to excellent fit. First, the demographic model showed that all demographic variables were associated with SS. Younger participants $(\beta=-.33, p=.003)$, women $(\beta=-$ $.33, p=.003)$, and those moving together with family members $(\beta=-.26, p=.017)$ experienced higher levels of SS.

The TIC model showed that GSE was positively associated with the initial level of SS ( $\beta=.35, p=.019)$. The TVC model showed that the linear slope, which was negative, was positively related to $\mathrm{T} 2$ Acculturative Stress $(\beta=.72, p=.001)-$ this means that who experienced more stress at T2 experienced a stronger decrease in SS during the follow-up. The quadratic slope was negatively related to T2 Socio-Cultural Adaptation Experiences $(\beta=$ 
$-.73, p=.005)$, and positively to T2 Acculturative Stress $(\beta=.72, p=.001)$; those who experienced more difficulties and stress at T2 showed a weaker U-curve in SS - their levels of SS did not start to increase after the initial drop.

T3 SS was negatively predicted by T2 Socio-Cultural Adaptation Experiences $(\beta=-$ $.91, p=.003)$ and by T2 Acculturative Stress $(\beta=-.54, p=.050)$; migrants who experienced more difficulties and stress at T2 had lower SS at T3. No concurrent relations were statistically significant.

\section{Discussion}

In a sample of Ingrian-Finns migrating from Russia to Finland, we set out to investigate long-term changes in psychological and social well-being. The results were rather complex, as all of our three different indices of well-being showed a different pattern of results. LS steadily increased throughout the migration process. In strong contrast, SE decreased during the same period of time. SS, on the other hand, showed the expected Ucurve; after an abrupt post-migration decrease, SS started to gradually recover, but did not reach pre-migration levels.

\section{Changes in LS, SE, and SS}

Perhaps the most surprising result of the present study is that changes in LS and SE were in opposite directions: LS increased and SE decreased. This was unexpected because SE has in cross-sectional research been considered one of the main determinants of LS (e.g., Campbell, 1981; Diener \& Diener, 1995; Kwan, Bond, \& Singelis, 1997; multitraitmultimethod studies (e.g., Lucas, Diener, \& Suh, 1996) have, however, suggested that the constructs are different). Studies measuring changes in LS and SE using a design comparable to ours are extremely few. However, one other study to employ a comparable quasiexperimental design also reported on dissociation between LS and SE. In this longitudinal study of low-income renters, becoming a homeowner increased LS, but left SE unaffected (Rohe \& Stegman, 1994). The review by Clark et al. (2008) on the effects of life events on LS did not find any life events that would have a positive impact on LS. However, the results 
reported on by Rohe and Stegman (1994) together with the current results suggest that some such events may exist.

As noted in the Introduction, SE may be a more inner-focused evaluation of one's worthiness, whereas judgments of LS could be based on both inner- and outer-focused evaluations (Chamberlain, 1988). Studies investigating the distinct correlates of SE and LS tend to support this line of reasoning. For instance, among children, school performance and physical ability - two very internal characteristics - are much more strongly correlated with SE than with LS (Huebner, Gilman, \& Laughlin, 1999). LS and SE also reveal different patterns of change throughout the life course. SE plummets in adolescence, after which it begins to increase steadily until the age of retirement, when it again abruptly and strongly decreases (Robins, Trzesniewski, Tracy, Gosling, \& Potter, 2002). This suggests that SE is high throughout mid-life, a time often characterized by its focus on activity, achievement, power, and control (e.g., Gove, Ortega, \& Style, 1989). By contrast, LS shows a U-curve which is at its lowest point in mid-life, thereafter steadily increasing into old age (Stone, Schwartz, Broderick, \& Deaton, 2010). Together such results suggest that SE may be determined by how well one is doing, whereas LS may be more about how happy one is. Perhaps our participants felt that they had not completely succeeded in surmounting the challenges and tasks imposed by migration, such as learning Finnish or entering the job market. Such failures could little by little have decreased their SE. However, they could still be satisfied with their over-all life situation.

Our results regarding SE are not similar to those reported on by Tartakovsky (2009a), who reported on an U-curve his sample of adolescent migrants to Israel. The gradual increase in SE that he reported on could be particular to the sample that he studied - the adolescents in that sample all attended Israeli schools and lived in kibbutzim and boarding schools, at which they gradually adopted a bi-cultural identity (Tartakovsky, 2009b). Acculturation may be more difficult for adult immigrants, whose levels of SE may continue decreasing for a longer period of time. Our results can also be interpreted as contradicting the idea that SE and 
Neuroticism refer to the same construct (Judge et al., 2002). Neuroticism, like other personality traits, may not change in response to life events (Specht, Egloff, \& Schmukle, 2011). However, our results suggest that external factors do influence SE.

Changes in SS followed the expected U-curve, decreasing from pre- to postmigration, but then starting to gradually increase. These results are fully consistent with our expectations and with the results reported on by Tartakovsky (2009a) regarding loneliness. The feeling that things were going well, as evidenced by the steady increase in LS, can have helped migrants to maintain and increase resources and form or strengthen social bonds (Gruber, Mauss, \& Tamir, 2011), thereby contributing to the final increase in SS.

\section{Individual-Level Predictors of SE, LS, and SS}

Demographic variables, with the exceptions of Subjective Economic Situation, were generally not very strong predictors of SE, LS, or SS. However, some interesting results did emerge. Although younger immigrants tended to have higher SE and SS, older participants, contrary to expectations, experienced a greater increase in LS after migration. One reason for this unexpected result could be that for young and middle-aged immigrants, SE, which generally decreased post-migration, may be a more important determinant of LS (Ryff, 1989). Older immigrants' LS may be determined more by other factors than their ability to function competently in their new environment.

Increasing confidence in our findings, several results were in the expected directions. Women, as expected (Lowenthal \& Haven, 1968), and also those moving with at least one family member, experienced higher levels of SS. Regarding economic situation, the results were also as anticipated: those who experienced more post-migration economic difficulties experienced a steeper decrease in SE and a weaker increase in LS. Previous research has established that one's economic situations impacts both SE (Twenge \& Campbell, 2002) and LS (Ackerman, \& Paolucci, 1983).

GSE revealed an interesting pattern. First, GSE was associated with high levels of both initial LS and SE. However, it was further related to a weaker increase in LS, and to a 
weaker decrease in SE. One explanation for the result regarding LS could be that GSE is important primarily due to its buffering function; those who scored high on GSE may have been more resilient towards pre-migration adversities, and migration may thus not have had as important a stress alleviating function in this group. The effect of GSE on the slope of SE suggests that high GSE may serve to protect SE. Consistent with this idea, research in organizational psychology shows that those scoring high on GSE tend to make self-serving attributions for unsuccessful performance (Silver, Mitchell, \& Gist, 1995). The migration experience generally challenged the SE of our participants. In such a context, self-serving attributions may have served to protect SE.

Regarding adaptation experiences, difficulties in adapting were associated with lower initial SE and lower post-migration LS and SS. Furthermore, such difficulties were associated with a steeper decrease in SE, and with a weaker upward turn in SS. Although no definite causal conclusions can be drawn, the results pertaining to SE suggest that SE may both affect migration outcomes, e.g., by serving an anxiety-buffering function (Greenberg et al., 1992), and itself be affected by these outcomes. Experiencing high levels of post-migration acculturative stress also had negative implications for well-being - acculturative stress was concurrently associated with lower LS, a weaker upward turn in SS, and prospectively associated with lower SE. Perceived discrimination, on the other hand, was not an important predictor of well-being. This unexpected finding can perhaps be explained by some recent results on perceived discrimination suggesting that it may have negative implications for well-being only for people who endorse a meritocracy worldview (Karklins, 2002); that is, who believe that status in society is earned, that anyone can get ahead, and that success stems from hard work. The extensive post-communist corruption that our participants are likely to have witnessed (Karklins, 2002) may have acted against a meritocratic world-view, making their well-being independent of the discrimination that they perceived.

In sum, our results regarding individual-level predictors suggest that post-migration economic situation, acculturative stress, and difficulties adjusting to a new culture, are 
important determinants of psychological and social well-being. Our results thus support the importance of also other than economic factors in migrants' adaptation (cf., Kessler et al., 1999; Kahneman \& Deaton, 2010). Furthermore, individual differences characteristics may also be important - consistent with previous research, GSE and initially high SE served a SE protecting function.

\section{Limitations and Conclusions}

Although the strongest aspect of the present research was its design, which included both pre- and post-migration measurement waves, the design was weak in the sense that it lacked a control group - this prevents us from presenting a strong causal account on the effects of migration. It would have been desirable to obtain responses from those potential migrants who did not migrate. Despite our efforts, we could not obtain their contact information.

Another limitation worth mentioning is that we cannot be certain of the direction of causality. We have adopted the common-sense view that life circumstances, such as income, influence well-being. However, it could also be other way around - those more satisfied with their lives may have larger incomes (Graham, Eggers, \& Sukhtankar, 2004). More satisfied people may also have stronger positive biases in their cognitions (Cummins \& Nistico, 2002), leading them to perceive less difficulties in adapting and less acculturative stress.

The sample size was another limitation of the present research. Although the sample was large enough to investigate direct relations between variables, it was not large enough to investigate possible interaction effects (Chaplin, 1991). It would, for instance, have been interesting to examine the interaction between GSE and acculturative stress on different indices of well-being.

Very few studies have studied migrants both before and after migration. The present sample of Ingrian-Finns, and Tartakovsky’s (2007; 2008; 2009a; 2009b) sample of unaccompanied minors migrating to Israel without their parents, are the rare exceptions. All conclusions must necessarily be tentative due to the uniqueness of the studies. This is further 
highlighted by the fact that our results were not identical to those reported on by Tartakovsky (2009a). Although differences in our results to some extent question the universalist approach that emphasizes commonalities in acculturation processes (Berry, Poortinga, Segall, \& Dasen, 2002), they do not altogether defy it. Regarding SS, our results were very similar to those reported on by Tartakovky (2009a). Furthermore, both samples also showed evidence of postmigration decrease in SE, the difference being that the adolescents migrating to Israel showed gradual recovery in levels of SE.

People regularly mispredict how much pleasure or displeasure future events will bring and, consequently, often strive after goals that do not maximize their happiness (Wilson \& Gilbert, 2005). Our results carry a mixed message to potential migrants contemplating whether or not to move - some aspects of well-being may improve, others worsen. Voluntary migration may be one of the few (Clark et al. 2008) life events to increase LS. However, to professionals working with migrants, our results suggest that migrants' are likely to suffer from poor SE and poor SS, and help should focus on rebuilding migrants' sense of self-worth and aiding them create social networks. Furthermore, already at the pre-migration stage, interventions designed to improve SE and GSE may prove worthwhile. As in other areas of life (e.g., academia (Schunk \& Ertmer, 2000), work (Gist, \& Mitchell, 1992), health (Schwarzer \& Renner, 2000)), those who believe that they will do well are more likely to do well. 
The Mixed Blessings of Migration 24

References

Ackerman, N., \& Paolucci, B. (1983). Objective and subjective income adequacy: Their relationship to perceived life quality measures. Social Indicators Research, 12, 25-48.

Aldwin, C. M. \& Revenson, T. A. (1987). Does coping help? A reexamination of the relation between coping and mental health. Journal of Personality and Social Psychology, 53, 237-248.

Andrews, F. M., \& Robinson, J. P. (1991). Measures of subjective well-being. In J. P. Robinson, P. R. Shaver, \& L. S. Wrightsman (Eds.), Measures of personality and social psychology attitudes (pp. 61-114). San Diego: Academic Press.

Bakker, W., Van Oudenhoven, J.P., \& Van der Zee, K.I. (2004). Attachment styles, personality, and Dutch emigrants' intercultural adjustment. European Journal of Personality, 18, 387-404.

Blakemore, K., \& Boneham, M. (1994). Age, race, and ethnicity. Buckingham, UK and Philadelphia, PA: Open University Press.

Beehr, T. A.., \& McGrath, J. E. (1992). Social support, occupational stress, and anxiety. Anxiety, Stress and Coping, 5, 7-19.

Berry, J.W. (2006). Stress perspectives on acculturation. In D.L. Sam \& J.W. Berry (Eds.), The Cambridge handbook of acculturation psychology (pp. 43-57). Cambridge, United Kingdom: Cambridge University Press.

Berry, J.W, Phinney, J.S., Sam, D.L., \& Vedder, P. (2006). Immigrant youth in cultural transitions: Acculturation, identity, and adaptation across national contexts. Mahwah, NJ: Erlbaum.

Berry, J.W., Poortinga,Y. H., Segall, M. H.,\&Dasen, P. R. (2002). Cross-cultural psychology: Research and applications (2nd ed.). Cambridge, UK: Cambridge University Press.

Berry, J. W., \& Sam, D. (1996). Acculturation and adaptation. In J. W. Berry, M. H. Segall, \& C. Kagitcibasi (Eds.), Handbook of crosscultural psychology: Vol 3. Social 
behavior and applications (pp. 291- 325). Boston: Allyn \& Bacon.

Brickman, P., \& Campbell, D. T. (1971). Hedonic relativism and planning the good society. In Appley, M. H. (Ed.): Adaptation level theory: A symposium (pp. 287-302) London: Academic Pres.

Brisset, C., Safdar, S., Lewis, J. R., \& Sabatier, C. (2010). Psychological and sociocultural adaptation of university students in France: The case of Vietnamese international students. International Journal of Intercultural Relations, 34, 413-426.

Brown, J. D., \& Marshall, M. A. (2001). Self-esteem and emotion: Some thoughts about feelings. Personality and Social Psychology Bulletin, 27, 575-584.

Brücker, H., \& Trübswetter, P. (2007). Do the best go west? An analysis of the self-selection of employed east-west migrants in Germany. Empirica, 34, 371-395.

Campbell, A. (1981). The sense of well-being in America. NewYork, NY: McGraw-Hill.

Chaplin, W. F. (1991), The next generation of moderator research in personality psychology. Journal of Personality, 59, 143-178.

Clark, A. E., Diener, E., Georgellis, Y., \& Lucas, R. E. (2008). Lags and leads in life satisfaction: A test of the baseline hypothesis. The Economic Journal, 118, F222F243.

Chamberlain, K. (1988). On the structure of well-being. Social Indicators Research, 20, 581604.

Cohen, S., \& Wills, T. A. (1985). Stress, social support, and the buffering hypothesis. Psychological Bulletin, 98, 310-357.

Cozzarelli, C. (1993). Personality and self-efficacy as predictors of coping with abortion. Journal of Personality and Social Psychology, 65, 1224-1236.

Cummins, R. A., \& Nistico, H. (2002). Maintaining life satisfaction: The role of positive cognitive bias. Journal of Happiness Studies, 3, 37-69.

Diener, E. (1984). Subjective well-being. Psychological Bulletin, 95, 542-575.

Diener, E., \& Diener, M. (1995). Cross-cultural correlates of life satisfaction. Journal of 
Personality and Social Psychology, 68, 653-663.

Diener E., Diener M., \& Diener C. (1995). Factors predicting the subjective well-being of nations. Journal of Personality and Social Psychology, 69, 851-864.

Diener, E., Lucas, R. E., \& Scollon, C. N. (2006). Beyond the hedonic treadmill: Revising the adaptation theory of well-being. American Psychologist, 61, 305-314.

Diener, E., Ng, W., Harter, J., \& Arora, R. (2010). Wealth and happiness across the world: Material prosperity predicts life evaluation, whereas psychosocial prosperity predicts positive feeling. Journal of Personality and Social Psychology, 99, 52-61.

Diener, E., Sandvik, E., \& Pavot, W. (1991). Happiness is the frequency, not the intensity, of positive versus negative affect. In F. Strack, M. Argyle, \& N. Schwarz (Eds.), Subjective well-being: An interdisciplinary perspective (pp. 119-140). Oxford: Pergamon.

Enders, C. K. \& Bandalos, D. L. (2001). The relative performance of full information maximum likelihood estimation for missing data in structural equation models. Structural Equation Modeling, 8, 430-457.

Fujita, F., \& Diener, E. (2005). Life satisfaction set point: Stability and change. Journal of Personality and Social Psychology, 88, $158-164$.

Gaston, J. E., \& Vogl, L. (2005). Psychometric properties of the general well-being index. Quality of Life Research, 14, 71-75.

Gist, M. E., \& Mitchell, T. R. (1992). Self-efficacy: A theoretical analysis of its determinants and malleability. Academy of Management Review, 17, 183-211.

Gove, W. R., Ortega, S. T., \& Style, C. B. (1989). The maturational and role perspectives on aging and self through the adult years: An empirical evaluation. American Journal of Sociology, 94, 1117-1145.

Graham, C., Eggers, A., \& Sukhtankar, S. (2004). Does happiness pay?: An exploration based on panel data from Russia. Journal of Economic Behavior and Organization, 55, 319-342. 
Greenberg, J., Solomon, S., Pyszczynski, T., Rosenblatt, A., Burling, J., Lyon, D., et al. (1992). Why do people need self-esteem? Converging evidence that self-esteem serves as an anxiety-buffering function. Journal of Personality and Social Psychology, 63, 913-922.

Gruber, J., Mauss, I. B., \& Tamir, M. (2011). A dark side of happiness? How, when, and why happiness is not always good. Perspectives on Psychological Science, 6, 222-233.

Headey, B., \& Wearing, A. J. (1989). Personality, life events and subjective well-being: Toward a dynamic equilibrium model. Journal of Personality and Social Psychology, 57, 731-739.

Heller, K. (1979). The effects of social support: Prevention and treatment implications. In A. P. Goldstein \& F. H. Kanfer (Eds.), Maximizing treatment gains: Transfer enhancement in psychotherapy (pp. 353-382). New York, NY: Academic.

Helliwell, J.F., Barrington-Leigh, C., Harris, A., \& Huang, H. (2010). International Evidence on the Social Context of Well-Being, In E. Diener, D. Kahneman and J.F. Helliwell (Eds.), International differences in well-being. London: Oxford University Press (p. 291-324).

Helliwell, J., \& Putnam, R. D. (2005). The social context of well-being. In F. A. Huppert, B. Keverne \& N. Baylis (Eds), The science of well-being. Oxford: Oxford University Press.

House, J. S. (1981). Work, stress, and social support. Reading, MA: Addison-Wesley.

Huebner, E. S., Gilman, R., \& Laughlin, J. E. (1999). A multimethod investigation of the multidimensionality of children's well-being reports: Discriminant validity of life satisfaction and self-esteem. Social Indicators Research, 46, 1-22.

Huppert, F. A., Marks, N., Clark, A., Siegrist, J., Stutzer, A., Vitterso, J., \& Wahrendorf, M. (2009). Measuring well-being across Europe: Description of the ESS Well-being Module and preliminary findings. Social Indicators Research, 91, 301-315.

Jasinskaja-Lahti, I., Liebkind, K., Jaakkola, M., \& Reuter, A. (2006). Perceived 
discrimination, social support networks, and psychological well-being among three immigrant groups. Journal of Cross-Cultural Psychology, 37, 293-311.

Jones, W. H., Freemon, J. E., \& Goswick, R. A. (1981). The persistence of loneliness: Self and other determinants. Journal of Personality, 49, 27-48.

Judge T.A., Erez A., Thoresen C.J., \& Bono J.E. (2002). Are measures of self-esteem, neuroticism, locus of control, and generalized self-efficacy indicators of a common core construct? Journal of Personality and Social Psychology, 83, 693-710.

Kahneman, D., \& Deaton, A. (2010). High income improves evaluation of life but not emotional well-being. Proceedings of the National Academy of Sciences, 107, 1648916493.

Karklins, R (2002). Typology of post-communist corruption. Problems of Post-Communism, $49,22-32$

Kessler, R. C., Mickelson, K. D., \& Williams, D. R. (1999). The prevalence, distribution, and mental health correlates of perceived discrimination in the United States. Journal of Health and Social Behavior, 40, 208-230.

Keyes, C. L. M. (1998) Social well-being. Social Psychology Quarterly, 61, 121-140.

Kuo, B. C. H., \& Roysircar, G. (2006). An exploratory study of cross-cultural adaptation of adolescent Taiwanese unaccompanied sojourners in Canada. International Journal of Intercultural Relations, 30, 159-183.

Kwan, V. S. Y., Bond, M. H. \& Singelis, T. M. (1997). Pan-cultural explanations for life satisfaction: Adding relationship harmony to self-esteem. Journal of Personality and Social Psychology, 73, 1038-1051.

Lazarus, R.S., \& Folkman, S. (1984). Stress, appraisal. and coping. New York: Springer Publishing.

Liebkind, K., Mannila, S., Jasinskaja-Lahti, I., Jaakkola, M., Kyntäjä, E., \& Reuter, A. (2004). Venäläinen, virolainen, suomalainen. Kolmen maahanmuuttajaryhmän kotoutuminen Suomessa. [A Russian, Estonian, and Finn. Comparison of the 
integration of three groups of migrants to Finland.] Helsinki: Gaudeamus.

Lowenthal, M., \& Haven, C. (1968). Interaction and adaptation: Intimacy as a critical variable. In B. L. Neugarten (Ed.), Middle age and aging: A reader in social psychology (pp. 390-400). Chicago: University of Chicago Press.

Lucas, R. E., Diener, E., \& Suh, E. (1996). Discriminant validity of well-being measures. Journal of Personality and Social Psychology, 7, 616-628.

Lykken, D., \& Tellegen, A. (1996). Happiness is a stochastic phenomenon. Psychological Science, 7, $186-189$.

Lönnqvist, J.-E., Jasinskaja-Lahti, I., \& Verkasalo, M. (2013). Rebound effect in personal values: Ingrian Finnish migrants' values two years after migration. Journal of CrossCultural Psychology, 44, 1122-1126.

Major, B., Kaiser, C., O’Brien, L., \& McCoy, S. (2007). Perceived discrimination as worldview threat or worldview confirmation: Implications for self-esteem. Journal of Personality and Social Psychology, 92, 1068-1086.

Manthorpe, J., \& Hettiaratchy, P. (1993). Ethnic minority elders in the UK. International Review of Psychiatry, 5, 171-178,

Markides K. S., \& Coreil, J. (1986). Review The health of Hispanics in the southwestern United States: an epidemiologic paradox, Public Health Reports, 101, 253-265.

Mähönen, T. A., \& Jasinskaja-Lahti, I. (2013). Acculturation expectations and experiences as predictors of ethnic migrants' psychological well-being. Journal of Cross-Cultural Psychology, 44, 786-806.

Muthén, L. K., \& Muthén, B. O. (2007). Mplus user's guide: Statistical analysis with latent variables (5th ed.). Los Angeles, CA: Author.

Oh, H. J., Ozkaya, E., \& LaRose, R. (2014). How does online social networking enhance life satisfaction? The relationships among online supportive interaction, affect, perceived social support, sense of community, and life satisfaction. Computers in Human Behavior, 30, 69-78. 
Pavot, W (1993). Review of the satisfaction with life scale. Psychological Assessment, 5 , 164-172.

Pinquart, M., \& Sörensen, S. (2000). Influences of socioeconomic status, social network, and competence on subjective well-being in later life: A metaanalysis. Psychology and Aging, 15, 187-224.

Putnam, R.D. (2000) Bowling alone: The collapse and revival of American community. New York: Simon and Schuster.

Robe, W. M., \& Stegman, M. A. (1994). The impacts of homeownership on the self esteem, percieved control and life satisfaction of low-income people. Journal of the American Planning Association, 60, 173-184.

Robins, R. W., Trzesniewski, K. H., Tracy, J. L., Gosling, S. D., \& Potter, J. (2002). Global self-esteem across the life span. Psychology and Aging, 17, 423-434.

Rogler, L. H., Cortes, D. E., \& Malgady, R. G. (1991). Acculturation and mental health status among Hispanics: Convergence and new directions for research. American Psychologist, 46, 585-597.

Rosenberg, M. (1965). Society and the adolescent self-image. Princeton: Princeton University Press.

Rudmin, F. (2009). Constructs, measurements and models of acculturation and acculturative stress. International Journal of Intercultural Relations, 33, 106-123.

Rumbaut, R. (1999). Assimilation and its discontents: Ironies and Paradoxes. In C. Hirschman, P. Kasinitz, \& J. DeWind (Eds.), The handbook of international migration (pp. 172-195). New York: Russell Sage Foundation.

Ryff, C. D. (1989). In the eye of the beholder: Views of psychological well-being among middle-aged and older adults. Psychology and Aging, 4, 195-210.

Saks, A. M., \& Ashforth, B. E. (2000). The role of dispositions, entry stressors, and behavioral plasticity theory in predicting newcomers' adjustment to work. Journal of Organizational Behavior, 21, 43-62. 
Schmitz, P.G. (2004). On the alternative five factor model: Structure and correlates. In R.M. Stelmack (Ed.), On the psychobiology of personality: Essays in honor of Marvin Zuckerman (pp. 65-87). Amsterdam: Elsevier.

Schwarzer, R., \& Jerusalem, M. (1995). Generalized self-efficacy scale. In J. Weinman, S. Wright, \& M. Johnston (Eds.): Measures in health psychology: A user's portfolio. Causal and control beliefs (pp. 35-37). Windsor, England: Nfer-Nelson.

Schwarzer, R., \& Renner, B. (2000). Social-cognitive predictors of health behavior: Action selfefficacy and coping self-efficacy. Health Psychology, 19, 487-495.

Schulz, U. \& Schwarzer, R. (2003). Soziale Unterstützung bei der Krankheitsbewältigung. Die Berliner Social Support Skalen (BSSS) [Social support in coping with illness: The Berlin Social Support Scales (BSSS)]. Diagnostica, 49, 73-82.

Schunk, D. H., and Ertmer, P. (2000). Self-regulation and academic learning: Self-efficacy enhancing interventions. In Boekaerts, M., Pintrich, P. R., and Zeidner, M. (eds.), Handbook of self-regulation (pp. 631-649). Academic Press, San Diego, CA.

Shen, B.-J., \& Takeuchi, D. T. (2001). A structural model of acculturation and mental health status among Chinese Americans. American Journal of Community Psychology, 29, $387-418$.

Silver, W. S., Mitchell, T. R., \& Gist, M. E. (1995). Responses to successful and unsuccessful performance: The moderating effect of self-efficacy on the relationship between performance and attributions. Organizational Behaviour and Human Decision Processes, 62, 286-299.

Specht, J., Egloff, B., \& Schmukle, S. C. (2011). Stability and change of personality across the life course: the impact of age and major life events on mean-level and rank-order stability of the Big Five. Journal of Personality and Social Psychology, 101, 862-882.

Stevenson B., Wolfers J. (2008). Economic growth and subjective well-being: Reassessing the Easterlin Paradox. Brookings Papers on Economic Activity, 1-102.

Stewart, D. E,. \& Yuen, T. (2011). A systematic review of resilience in the physically ill. 
Psychosomatics, 52, 199-209.

Stone, A. A., Schwartz, J. E., Broderick, J. E., \& Deaton, A. (2010). A snapshot of the age distribution of psychological well-being in the United States. Proceedings of the National Academy of Sciences, USA, 107, 9985-9990.

Tartakovsky, E. (2007). A longitudinal study of acculturative stress and homesickness: Highschool adolescents immigrating from Russia and Ukraine to Israel without parents. Social Psychiatry and Psychiatric Epidemiology, 42, 485-494.

Tartakovsky, E. (2008). Psychological well being and ethnic identities of Jewish adolescents planning emigration from Russia and Ukraine to Israel: Changes during the postperestroika period. International Journal of Intercultural Relations, 32, 553-564.

Tartakovsky, E. (2009a). The psychological well-being of unaccompanied minors: A longitudinal study of adolescents immigrating from Russia and Ukraine to Israel without parents. Journal of Research on Adolescence, 19, 177-204.

Tartakovsky, E. (2009b). Cultural identities of adolescent immigrants: A three-year longitudinal study including the pre-migration period. Journal of Youth and Adolescence, 38, 654-671.

Tennen, H., \& Herzberger, S. (1987). Depression, self-esteem, and the absence of selfprotective attributional biases. Journal of Personality and Social Psychology, 52, 7280.

Terry, D. J. (1994). Determinants of coping: the role of stable and situational factors. Journal of personality and Social Psychology, 66, 895-910.

Thoits, P. A. (1985). Social support and psychological well-being: Theoretical possibilities. In I. G. Sarason \& B. R. Sarason (Eds.), Social support: Theory, research and application (pp. 51-72). Dordrecht, the Netherlands: Martinus Nijhoff.

Turner, J.C. (1982). Towards a cognitive redefinition of the social group. In H. Tajfel (Ed.), Social identity and intergroup relations (pp. 15-40). Cambridge: Cambridge University Press. 
Twenge, J. M., \& Campbell, W. K. (2002). Self-esteem and socioeconomic status: A metaanalytic review. Personality and Social Psychology Review, 6, 59-71.

Ward, C., Leong, C.H., \& Low, M. (2004). Personality and sojourner adjustment: An exploration of the "Big Five", and the "Cultural Fit" proposition. Journal of CrossCultural Psychology, 35, 137-151.

Ward, C., \& Kennedy, A. (1999). The measurement of sociocultural adaptation. International Journal of Intercultural Relations, 23, 659-677.

Ward, C., Okura, Y., Kennedy, A., \& Kojima, T. (1998). The U-curve on trial: A longitudinal study of psychological and socio-cultural adjustment during cross-cultural transition. International Journal of Intercultural Relations, 22, 277-291.

Wilson, T. D., \& Gilbert, D. T. (2005). Affective forecasting knowing what to want. Current Directions in Psychological Science, 14, 131-134.

Ying, Y. W. (2005). Variation in acculturative stressors over time: A study of Taiwanese students in the United States. International Journal of Intercultural Relations, 29, 5971.

Young, K. W. (2006). Social support and life satisfaction. International Journal of Psychosocial Rehabilitation, 10, 155-164.

Zhu, X., Woo, S. E., Porter, C., \& Brzezinski, M. (in press). Pathways to happiness: From personality to social networks and perceived support. Social Networks. 
Table 1

Means, Standard Deviations and Alpha Internal Consistency Reliabilities of our Measures

\begin{tabular}{|c|c|c|c|c|}
\hline Measures & $M$ & $S D$ & $\alpha$ & $N$ \\
\hline \multicolumn{5}{|l|}{ LS } \\
\hline LS T0 & 2.80 & 0.91 & .81 & 204 \\
\hline LS T1 & 3.44 & 0.76 & .73 & 153 \\
\hline LS T2 & 3.44 & 0.77 & .76 & 130 \\
\hline LS T3 & 3.54 & 0.71 & .74 & 81 \\
\hline
\end{tabular}

SE

SE T0

$\begin{array}{llll}4.31 & 0.60 & .70 & 215\end{array}$

SE T1

$\begin{array}{llll}4.23 & 0.63 & .77 & 153\end{array}$

SE T2

$\begin{array}{llll}4.23 & 0.62 & .74 & 128\end{array}$

SE T3

$\begin{array}{llll}4.06 & 0.52 & .56 & 82\end{array}$

SS

SS T0

$\begin{array}{llll}4.56 & 0.55 \quad .92 & 217\end{array}$

SS T1

$\begin{array}{llll}4.28 & 0.68 & .93 & 154\end{array}$

SS T2

$\begin{array}{llll}4.34 & 0.67 & .94 & 131\end{array}$

SS T3

$\begin{array}{llll}4.40 & 0.59 & .93 & 85\end{array}$

Time-Varying Covariates

Adaptation Experiences T1

$\begin{array}{llll}1.98 & 0.54 & .93 & 151\end{array}$

Adaptation Experiences T2

$\begin{array}{llll}1.97 & 0.54 & .93 & 129\end{array}$

Stress T1

$\begin{array}{llll}2.99 & 1.44 & .86 & 149\end{array}$

Stress T2

$\begin{array}{llll}3.05 & 1.37 & .86 & 132\end{array}$

Perceived Discrimination T1

$\begin{array}{llll}1.71 & 0.73 & .84 & 149\end{array}$

Perceived Discrimination T2

$\begin{array}{llll}1.66 & 0.63 & .77 & 125\end{array}$

Subjective Economic Situation T0

$\begin{array}{llll}3.04 & 1.04 & - & 215\end{array}$

Subjective Economic Situation T1

$\begin{array}{llll}3.35 & 0.90 & - & 143\end{array}$

Subjective Economic Situation T2

$\begin{array}{llll}3.35 & 0.88 & - & 130\end{array}$

Subjective Economic Situation T3

$\begin{array}{llll}3.06 & 0.88 & - & 82\end{array}$

Time-Invariant Covariates

Self-Efficacy

$\begin{array}{llll}3.82 & 0.67 & .91 & 211\end{array}$


Table 2

Indices of Model Fit

$$
\chi^{2}(\mathrm{df}) \quad \mathrm{CFI} \quad \text { RMSEA }
$$

$\begin{array}{lrll}\text { Self-Esteem linear } & 31.70(7) & 0.859 & .127 \\ \text { Self-Esteem quadr. } & 31.68(6) & 0.854 & .140 \\ \text { Self-Esteem free } & 28.39(5) & 0.867 & .146 \\ \text { Life satisfaction linear } & 44.73(7) & 0.598 & .159 \\ \text { Life satisfaction quadr. } & 22.66(6) & 0.822 & .114 \\ \text { Life satisfaction free } & 9.89(5) & 0.948 & .068 \\ \text { Social support linear } & 31.61(5) & 0.732 & .155 \\ \text { Social support quadr. } & 1.26(1) & 0.997 & .034 \\ \text { Social support free } & 1.20(3) & 1.00 & .000\end{array}$


The Mixed Blessings of Migration 36

\section{Figure captions.}

Figure 1. Changes in Life Satisfaction (top panel), Self-Esteem (center panel), and Social Support (bottom panel) as a function of time. I.e., at the pre-migration stage (T0), at approximately half a year (T1), two (T2), and three (T3) years after migration. 